\title{
Internal Combustion Engine Control Based on CFM Strategy
}

\author{
Ali Reza Zarei, Mohammad Sadegh Dahideh, Mohammad Najafi, Mehran Afshar and \\ Yaser Barmayeh \\ Department of Electrical Engineering, Delvar Branch, Islamic Azad University, \\ Delvar, Iran \\ Yaser.barmayeh2014@gmail.com
}

\begin{abstract}
Internal combustion (IC) engines are optimized to meet exhaust emission requirements with the best fuel economy. The mean-value engine model can be used to validate control strategies for different types of controllers that are model-based. The equations that are used to calculate the outputs of the model are approximated over an engine cycle. A significant advantage of the mean-value engine model is its low computational throughput which makes it possible for real-time simulation. In order to reduce engine emissions and improving engine fuel economy, closed loop combustion control, which requires cycleto-cycle combustion measurement such as cylinder pressure, is a necessity. The addition of a cylinder pressure signal to a mean value engine model will allow for developing closed loop combustion control strategies (or other strategies that involve cylinder pressure) to be validated. This is because the cylinder pressure model can produce a cylinder pressure signal for a complete engine operational map and a mean value engine model can produce real world engine parameters and conditions. The performance of the baseline computed fuel controller is compared with that of a baseline proportional, integral, and derivative (PID) controller.
\end{abstract}

Keywords: C engine, fuel ratio, port fuel injection, direct injection, baseline controller, computed fuel controller

\section{Introduction}

The internal combustion (IC) engine is designed to produce power from the energy that is contained in its fuel. More specifically, its fuel contains chemical energy and together with air, this mixture is burned to output mechanical power. There are various types of fuels that can be used in IC engines which include petroleum, bio-fuels, and hydrogen. In an internal combustion engine, a piston moves up and down in a cylinder and power is transferred through a connecting rod to a crank shaft. The continual motion of the piston and rotation of the crank shaft as air and fuel enter and exit the cylinder through the intake and exhaust valves is known as an engine cycle. The first and most significant engine among all internal combustion engines is the Otto engine, which was developed by Nicolaus A. Otto in 1876 [18]. In his engine, Otto created a unique engine cycle that consisted of four piston strokes. These strokes are:

1. Intake stroke

2. Compression stroke

3. Expansion stroke

4. Exhaust stroke 
Modeling of an entire IC engine is a very important and complicated process because engines are nonlinear, multi inputs-multi outputs and time variant. One purpose of accurate modeling is to save development costs of real engines and minimizing the risks of damaging an engine when validating controller designs. Nevertheless, developing a small model, for specific controller design purposes, can be done and then validated on a larger, more complicated model. Analytical dynamic nonlinear modeling of internal combustion engine is carried out using elegant Euler-Lagrange method compromising accuracy and complexity [912]. An empirical dynamic nonlinear model of the system is then developed on the bases of neural network and/or neuro-fuzzy. The developed models are verified using several testing approaches such as overlapping, power spectral density and correlation tests [13-15]. The sum of the fuel that is injected into the cylinder by the port fuel injector and the direct fuel injector is the total fuel, $\dot{M}_{\text {Fuel }}$. The amount of fuel injected by one injector divided by the sum of the two is the fuel ratio of PFI to DI. The fuel ratio can be used to determine which fuel system should have a larger impact on how much fuel is injected into the cylinder. Since a direct fuel injector has immediate injection of its fuel with significant charge cooling effect, it can have a quicker response to the desired amount of fuel that is needed by an engine. Although a port fuel injector may have a slower response due to its wall-wetting dynamics, the fuel ratio will impact the combustion characteristics of an engine. Fuel ratio also can be used to regulate or control two fuel types. For example, an engine may have the ability to run on gasoline and ethanol. The gasoline could be injected by a port fuel injector, while the ethanol could be injected by a direct injector. Although, implementation of this may require to separate fuel lines and separate fuel tanks, the ratio of gasoline to ethanol, or two other types of fuels, may be of interest to future engine control designers [16-17].

Controller is a device which can sense information from linear or nonlinear system (e.g., IC engine) to improve the systems performance [18-21]. The main targets in designing control systems are stability, good disturbance rejection, and small tracking error[21]. Several IC engine are controlled by linear methodologies (e.g., Proportional-Derivative (PD) controller, Proportional- Integral (PI) controller or Proportional- Integral-Derivative (PID) controller), but when IC engine works in various situation and have uncertainty in dynamic models this technique has limitations. Strong mathematical tools used in new control methodologies to design nonlinear robust controller with an acceptable performance (e.g., minimum error, good trajectory, disturbance rejection). Baseline computed fuel controller (BCFC) is an influential nonlinear controller to certain and partly uncertain systems which it is based on feedback linearization and computes the required outputs using the nonlinear feedback control law. When all dynamic and physical parameters are known, BCFC works superbly. There have been several engine controller designs over the past 40 years in which the goal is to improve the efficiency and exhaust emissions of the automotive engine. A key development in the evolution was the introduction of a closed loop fuel injection control algorithm by Rivard in the 1973 [7]. This strategy was followed by an innovative linear quadratic control method in 1980 by Cassidy [8] and an optimal control and Kalman filtering design by Powers [9]. Although the theoretical design of these controllers was valid, at that time it was not realistic to implement such complex designs. Therefore, the production of these designs did not exist and engine designers did adopt the methods [19-21]. Due to the increased production of the microprocessor in the 1990's, it became practical to use these microprocessors in developing more complex control and estimation algorithms that could potentially be used in production automotive engines. Specific applications of fuel ratio control based on observer measurements in the intake manifold were developed by Benninger in 1991 [10]. Another approach was to base the observer on measurements of exhaust gases measured by the oxygen sensor and on the throttle position, which was researched by Onder 
[11]. These observer ideas used linear observer theory. Hedrick also used the measurements of the oxygen sensor to develop a nonlinear, sliding mode approach to control the A/F ratio [12]. All of the previous control strategies were applied to engines that used only port fuel injections, where fuel was injected in the intake manifold. The development of these control strategies for direct injection was not practical because the production of direct injection automobiles did not begin until the mid 1990's. Mitsubishi began to investigate combustion control technologies for direct injection engines in 1996 [13]. Furthermore, engines that used both port fuel and direct systems appeared a couple years ago, leading to the interest of developing the corresponding control strategies. Current production $\mathrm{A} / \mathrm{F}$ ratio controllers use closed loop feedback and feed forward control to achieve the desired stoichiometric mixture. These controllers use measurements from the oxygen sensor to control the desired amount of fuel that should be injected over the next engine cycle and have been able to control the A/F very well.

This paper is organized as follows. In section 2, main subject of dynamic formulation of IC engine is presented. A methodology of proposed baseline computed fuel controller is presented in section 3. In section 4, the baseline controller and proposed methodology are compared and discussed. In section 5, the conclusion is presented.

\section{Theory}

Dynamic of IC Engine: Dynamic modeling of IC engine is used to describe the nonlinear behavior of IC engine, design of model based controller such as pure variable structure controller based on nonlinear dynamic equations, and for simulation. The dynamic modeling describes the relationship between fuel to air ratio to PFI and DI and also it can be used to describe the particular dynamic effects (e.g., motor pressure, angular speed, mass of air in cylinder, and the other parameters) to behavior of system[1].

The equation of an IC engine governed by the following equation $[1,4,10,12,15-19]$ :

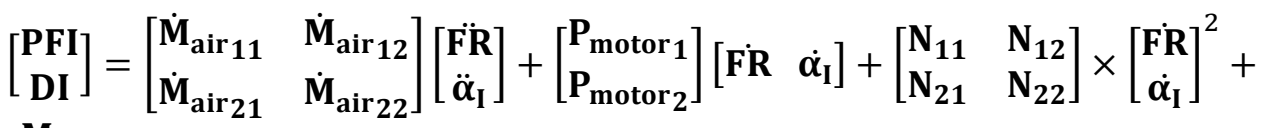

$$
\begin{aligned}
& {\left[\begin{array}{l}
\mathbf{M}_{\mathbf{a}_{1}} \\
\mathbf{M}_{\mathbf{a}_{2}}
\end{array}\right]}
\end{aligned}
$$

Where $P F I$ is port fuel injector, $D I$ is direct injector, $\dot{\mathbf{M}}_{\text {air }}$ is a symmetric and positive define mass of air matrix, $\mathbf{P}_{\text {motor }}$ is the pressure of motor, $N$ is engine angular speed and $\mathbf{M}_{\mathbf{a}}$ is matrix mass of air in cylinder. Fuel ratio and exhaust angle are calculated by [18-19]:

$$
\begin{aligned}
& {\left[\begin{array}{c}
F \ddot{R}_{a} \\
\ddot{\alpha}_{I a}
\end{array}\right]=\left[\begin{array}{ll}
\dot{M}_{\text {air } 11} & \dot{M}_{\text {air } 12} \\
\dot{M}_{\text {air } 21} & \dot{M}_{\text {air } 22}
\end{array}\right]^{-1}\left\{\left[\begin{array}{c}
P F I \\
D I
\end{array}\right]-\left\{\left[\begin{array}{l}
P_{\text {motor }_{1}} \\
P_{\text {motor }_{2}}
\end{array}\right]\left[\begin{array}{ll}
F_{R} & \dot{\alpha}_{I_{a}}
\end{array}\right]+\left[\begin{array}{ll}
N_{11} & N_{12} \\
N_{21} & N_{22}
\end{array}\right] \times\right.\right.} \\
& \left.\left.\left[\begin{array}{c}
F \dot{R}_{a} \\
\dot{\alpha}_{I_{a}}
\end{array}\right]^{2}+\left[\begin{array}{c}
M_{a_{1}} \\
M_{a_{2}}
\end{array}\right]\right\}\right\}
\end{aligned}
$$

The above target equivalence ratio calculation will be combined with fuel ratio calculation that will be used for controller design purpose.

Baseline Methodology: The design of a baseline methodology to control the fuel ratio was very straight forward. Since there was an output from the fuel ratio model, this means that 
there would be two inputs into the baseline controller. Similarly, the output of the controller result from the two control inputs of the port fuel injector signal and direct injector signal. In a typical PID method, the controller corrects the error between the desired input value and the measured value. Since the equivalence ratio and fuel ratio are the two measured signals, two controllers were cascaded together to control the PFI and DI inputs. The first was a PID controller that corrected the error between the desired equivalence ratio and the measured equivalence ratio; while the second was only a proportional integral (PI) controller that corrected the fuel ratio error.

$$
\begin{aligned}
& e_{1}(t)=\alpha_{\text {target }}(t)-\alpha_{d}(t) \\
& e_{2}(t)=\text { Fuel ratio }_{a}(t)-\text { Fuel Ratio } d \\
& P F I_{\alpha}=K_{p_{a}} e_{1}+K_{V_{a}} \dot{e_{1}}+K_{I_{a}} \sum e_{1} \\
& D I_{\alpha}=K_{p_{b}} e_{1}+K_{V_{b}} e_{1}+K_{I_{b}} \sum e_{1} \\
& P F I_{F}=\left(K_{p_{c}} e_{2}+K_{I_{c}} \sum e_{2}\right) \times P F I_{\alpha} \\
& D I_{F}=D I_{\alpha}
\end{aligned}
$$

\section{Methodology}

Computed fuel optimization (CFM) is a powerful nonlinear optimized supervisory method, which it is widely used in control of fuel ratio of IC engine. It is based on feedback linearization and computes the required engine fuels using the nonlinear feedback control law. This controller works very well when all dynamic and physical parameters are known or partly unknown. In practice, most of physical systems (e.g., IC engines) parameters are unknown or time variant, therefore, BCFC used to compensate dynamic equation of IC engine. Research on BCFC is significantly growing on IC engine application. Vivas and Mosquera have proposed a predictive functional controller and compare to computed fuel methodology (CFM) for tracking response in uncertain environment. However both controllers have been used in feedback linearization, but predictive strategy gives better result as a performance. When all dynamic and physical parameters are known, CFM works fantastically. The central idea of CFM is feedback linearization so, originally this algorithm is called computed fuel controller. It has assumed that the desired PFI for the IC engine $\boldsymbol{P F} \boldsymbol{I}_{\boldsymbol{d}}(\boldsymbol{t})$, as determined, by a path planner. Defines the error as:

If an alternative linear state-space equation in the form $\dot{\boldsymbol{x}}=\boldsymbol{A} \boldsymbol{x}+\boldsymbol{B} \boldsymbol{U}$ can be defined as

$$
\dot{x}=\left[\begin{array}{ll}
\mathbf{0} & \boldsymbol{I} \\
\mathbf{0} & \mathbf{0}
\end{array}\right] \boldsymbol{x}+\left[\begin{array}{l}
\mathbf{0} \\
\boldsymbol{I}
\end{array}\right] \boldsymbol{U}
$$

With $U=\left[\begin{array}{l}P_{\text {motor }_{1}} \\ P_{\text {motor }_{2}}\end{array}\right]\left[\begin{array}{ll}F R & \dot{\alpha}_{I_{a}}\end{array}\right]+\left[\begin{array}{cc}N_{11} & N_{12} \\ N_{21} & N_{22}\end{array}\right] \times\left[\begin{array}{c}F \dot{R}_{a} \\ \dot{\alpha}_{I_{a}}\end{array}\right]^{2}+\left[\begin{array}{c}M_{a_{1}} \\ M_{a_{2}}\end{array}\right]$ and this is known as the Brunousky canonical form. By (8) and (9) the Brunousky canonical form can be written in terms of the state $\boldsymbol{x}=\left[\boldsymbol{e}^{T} \dot{e}^{T}\right]^{T}$ as [1]: 


$$
\frac{d}{d t}\left[\begin{array}{l}
e \\
\dot{e}
\end{array}\right]=\left[\begin{array}{ll}
0 & I \\
0 & 0
\end{array}\right] \cdot\left[\begin{array}{l}
e \\
\dot{e}
\end{array}\right]+\left[\begin{array}{l}
0 \\
I
\end{array}\right] U
$$

This is a nonlinear feedback control law that guarantees tracking of IC engine trajectory. Selecting proportional-plus-derivative (PD) feedback for $\mathrm{U}(\mathrm{t})$ results in the PD-FELC ;

$$
\begin{aligned}
& P F I= \\
& P \ddot{F} I_{d}\left\{\left(F R_{d}+K_{p} e+K_{v} \dot{e}\right) \times\left[\begin{array}{ll}
\dot{M}_{\mathrm{air}_{11}} & \dot{\mathrm{M}}_{\mathrm{air}_{12}} \\
\dot{\mathrm{M}}_{\text {air } 21} & \dot{\mathrm{M}}_{\text {air 22 }}
\end{array}\right]\right\}+\left[\begin{array}{l}
P_{\text {motor }_{1}} \\
P_{\text {motor }_{2}}
\end{array}\right]\left[\begin{array}{ll}
F R & \dot{\alpha}_{I_{a}}
\end{array}\right]+ \\
& {\left[\begin{array}{ll}
N_{11} & N_{12} \\
N_{21} & N_{22}
\end{array}\right] \times\left[\begin{array}{c}
F \dot{R}_{a} \\
\dot{\alpha}_{I_{a}}
\end{array}\right]^{2}+\left[\begin{array}{l}
M_{a_{1}} \\
M_{a_{2}}
\end{array}\right]}
\end{aligned}
$$

According to the linear system theory, convergence of the tracking error to zero is guaranteed. Where $\boldsymbol{K}_{\boldsymbol{p}}$ and $\boldsymbol{K}_{\boldsymbol{v}}$ are the controller gains.

\section{Results and Discussion}

The CFM controller of the A/F ratio and fuel ratio was implemented and simulated in Matlab/Simulink. Simulations that model real world A/F ratio and fuel ratio situations were conducted, similar to simulations of the baseline controller. The main difference between each simulation was how the closed loop system responded to various air flow inputs. For comparison purposes to the baseline controller simulations, the same target equivalence ratio was taken to be unity and the same target fuel ratio was 0.6.

The first simulation uses a constant value for the air input, which models a situation that the throttle (air) opens at a constant angle. The constant value was chosen to be 0.15 and the states of the closed loop system are shown in Figure 1.

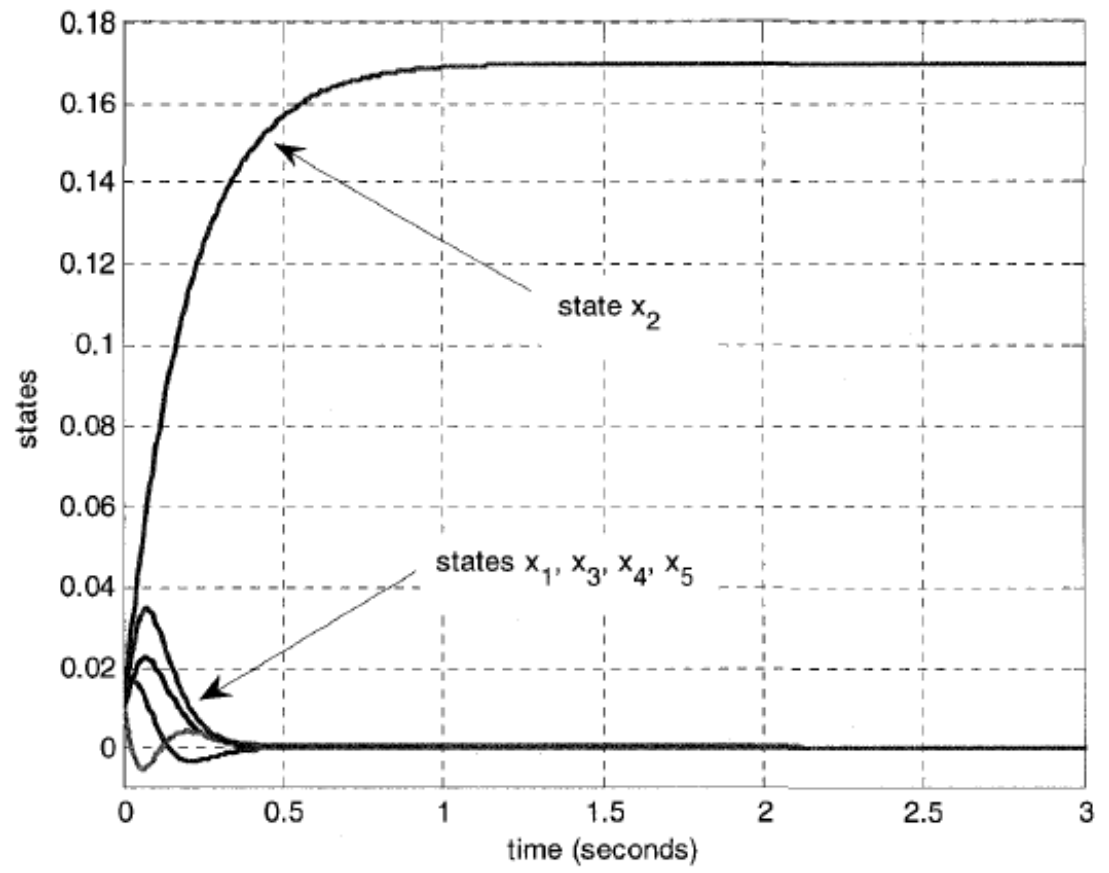

Figure 1. State of the System for CFM Method 
The initial conditions of the states of the transformed equivalence ratio and fuel ratio model were chosen to be 0.01 as can be seen in Figure 1. The states different and are forced to the CFM manifold, $s=0$, in a finite time of less than 1 second. These states remained at zero for all future time, which showed that the CFM theory was valid. Meanwhile the state $X 2$ does reach the CFM manifold due to the constant disturbance input but it reaches steady state in finite time. From the state space model, the state $X 2$ is affected by the input air disturbance. The CFM isolated that state and decoupled it from the remaining states, causing the rest of the states to reach the correct surface of the system. Therefore, the input air disturbance affect on the equivalence ratio and fuel ratio was minimized. Figure 2 shows this state.

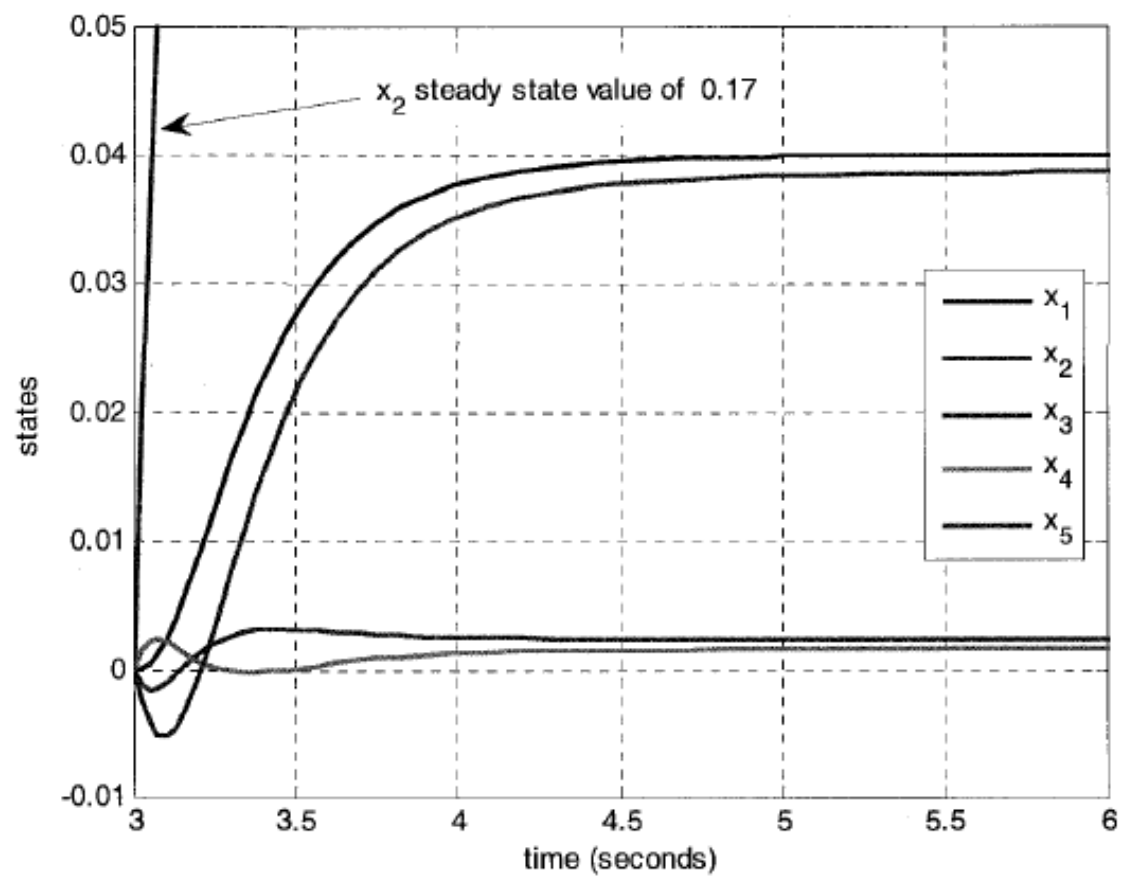

Figure 2. States for the System Reach to Desired Equivalence and Fuel Ratios

\section{Conclusion}

The ability to use CFM theory on a MIMO case was significant. Extending this theory to achieve and maintain any target output (desired equivalence ratio and fuel ratio) is the most important contribution of this research. The control target is to maintain the fuel ratio at stoichiometry and the fuel ratio to a desired value between zero and one (the best number is 0.6). Compared to the baseline controller, the proposed controller had a significantly lower steady state error in response to the random input disturbance. The percent overshoot for the CFM was also noticeably better and in response to the step input, had a better settling time than the baseline controller.

\section{References}

[1] J. Heywood, "Internal Combustion Engine Fundamentals", McGraw-Hill, New York, (1988).

[2] C. Ferguson, "Internal Combustion Engines: Applied Thermosciences", John Wiley \& Sons, Inc., New York, (2001). 
[3] L. Guzzella, "Introduction to Modeling and Control of Internal Combustion Engine Systems" Springer, New York, (2004).

[4] J. Ramos, "Internal Combustion Engine Modeling", Hemisphere Publishing corporation, New York, (1989).

[5] G. Blair, "Design and Simulation of Four Stroke Engines", Society of Automotive Engineers, Warrendale, $\mathrm{Pa},(1999)$.

[6] G. Zhu, "Closed-Loop Ignition Timing Control for SI Engines Using Ionization Current Feedback," IEEE Trans on Control Systems, (2007) May, pp. 416-427.

[7] I. Haskara, "On Combustion Invariants for MBT Timing Estimation and Control," in ASME Internal Combustion Engine Division, (2004).

[8] J. Dawson, "An experimental and Computational Study of Internal Combustion Engine Modeling for Controls Oriented Research” Ph.D. Dissertation, The Ohio State University, (2005).

[9] B. Lee, "Methodology for the Static and Dynamic Model Based Engine Calibration and Optimization" Ph.D. Dissertation, The Ohio State University, (2005).

[10] S. A. Kalogirou, "Artificial intelligence for the modeling and control of combustion processes: a review", Progress in Energy and Combustion Science, science direct, (2003).

[11] J. G. Rivard, "Closed-loop Electronic Fuel Injection Control of the IC Engine," in Society of Automotive Engineers, (1973).

[12] J. F. Cassidy, "On the Design of Electronic Automotive Engine Controls using linear Quadratic Control Theory", IEEE Trans on Control Systems, vol. AC-25, (1980) October.

[13] W. E. Powers, "Applications of Optimal Control and Kalman Filtering to Automotive Systems", International Journal of Vehicle Design, vol. Applications of Control Theory in the Automotive Industry, (1983).

[14] N. F. Benninger, "Requirements and Perfomance of Engine Management Systems under Transient Conditions," in Society of Automotive Engineers, (1991).

[15] C. H. Onder, "Model-Based Multivariable Speed and Air-to-Fuel Ratio Control of an SI Engine," in Society of Automotive Engineers, (1993).

[16] S. B. Cho, "An Observer-based Controller Design Method for Automotive Fuel-Injection Systems," in American Controls Conference, (1993), pp. 2567-2571.

[17] T. Kume, "Combustion Technologies for Direct Injection SI Engine," in Society of Automotive Engineers, (1996).

[18] F. Piltan, N. Sulaiman, I. A. Talooki and P. Ferdosali, "Control of IC Engine: Design a Novel MIMO Fuzzy Backstepping Adaptive Based Fuzzy Estimator Variable Structure Control”, International Journal of Robotics and Automation, vol. 2, no. 5, (2011), pp. 360-380.

[19] F. Piltan, A. Jalali, N. Sulaiman, A. Gavahian and S. Siamak, "Novel Artificial Control of Nonlinear Uncertain System: Design a Novel Modified PSO SISO Lyapunov Based Fuzzy Sliding Mode Algorithm," International Journal of Robotics and Automation, vol. 2, no. 5, (2011) pp. 298-316.

[20] F. Piltan, N. Sulaiman and I. A. Talooki, "Evolutionary Design on-line Sliding Fuzzy Gain Scheduling Sliding Mode Algorithm: Applied to Internal Combustion Engine," International Journal of Engineering Science and Technology, vol. 3, no. 10, (2011), pp. 7301-7308.

[21] F. Piltan, N. B. Sulaiman, I. A. Talooki and P. Ferdosali”, Designing On-Line Tunable Gain Fuzzy Sliding Mode Controller Using Sliding Mode Fuzzy Algorithm: Applied to Internal Combustion Engine”, world applied science journal (WASJ), vol. 15, no. 3, (2011), pp. 422-428. 
International Journal of Hybrid Information Technology Vol.8, No.2 (2015) 